\title{
Overall Diversity of Fruit-Feeding Butterflies (Lepidoptera: Nymphalidae) Along Vertical Gradient in a Peat Swamp Forest, Kota Samarahan, Sarawak
}

\author{
CHRISTHARINA GINTORON*1 \& FATIMAH ABANG ${ }^{2}$ \\ ${ }^{I}$ Center for Pre-University Studies, Universiti Malaysia Sarawak, Kota Samarahan, 94300, Sarawak, \\ Malaysia; ${ }^{2}$ Department of Zoology, Faculty of Resource Science and Technology, Universiti Malaysia \\ Sarawak, Kota Samarahan, 94300, Sarawak, Malaysia
}

\begin{abstract}
A study which aims to investigate the vertical distribution pattern of nymphalids had been conducted in a peat swamp forest of Kota Samarahan, Sarawak. This 60-day sampling period which utilised baited traps as the main sampling method, had resulted to 104 individuals from both ground and canopy levels. The lower stratum revealed a higher diversity index $\left(\mathrm{H}^{\prime}=1.17466\right)$ in comparison with the canopy stratum. Nymphalinae represents the most diverse subfamily at both levels, dominating almost half of the total individuals respectively. In general, species richness and abundance decrease with the increasing strata height, and was observed in all subfamilies. Analyses on the relationship between forewing length and strata revealed significant result for both male and female of Satyrinae, while for body design, it was only significant for male Nymphalinae and female Satyrinae. Overall, the study on strata preference of the nymphalids had led to a better understanding on their dependence on microclimatic conditions, as well as the status of their habitat.
\end{abstract}

Keywords: Butterflies, peat swamp, Sarawak, vertical distribution

\section{INTRODUCTION}

Vertical studies have been established around the world and utilised as one of the major methods in assessing information on species diversity (Butler, 2005). Investigation on the forest canopy has enhanced and improved to be more descriptive, and thus this approach has assist majorly in the assessment of ecological study (Butler, 2005). As a result, stratification along the vertical gradient has produced specific patterns in terms of abundance and species richness which has the influence from the habitat itself.

In the tropical rainforest, previous and current canopy studies usually took place in primary mixed dipterocarp forest (Beck \& Schulze, 2000; DeVries \& Walla, 2001; Schulze et al., 2001). Hence, due to the lack of documentation at the other types of forest, this study was conducted in a secondary peat swamp forest. Characterised with damp and excessive drainage, in comparison with the other types of forest, the vegetation and stratification are different, and specifically for entomofauna which are host plant-specific, the diversity is expected to be varied.

The fruit-feeding butterfly is a good indicator tool as they characterised the habitat they sustained (Fermon et al., 2000; Schulze et al., 2001). By sampling these nymphalids with baited traps installed at both strata, their faunistic composition can be assessed and thus the general patterns of vertical distribution can be produced.

The objectives of this study are as followed;

a) To examine the vertical distribution of fruit-feeding butterflies in peat swamp forest

b) To relate between butterflies preferences at different heights of forest layers and its morphological characteristics 


\section{MATERIALS \& METHODS}

\section{Study site}

This study was carried out at a peat swamp forest in Universiti Malaysia Sarawak, which is located at Kota Samarahan $\left(01^{\circ} 27^{\prime}, 48^{\prime}{ }^{\prime} \mathrm{N}\right.$ and $\left.11^{\circ} 27^{\prime}, 30^{\prime \prime} \mathrm{E}\right)$, Sarawak, Malaysia. Study site was considered as a secondary peat swamp forest with forest degradation in consequence with the logging activities about 50 years ago (Zainudin, 2006; Abang \& Hill, 2006). Vegetation types include a few epiphytes such as Asplenium nidus, Polypodiaceae, and Drynari; families Sapotaceae, Euphorbiaceae and Moraceae, such as the Macaranga sp. and Ficus sp.

\section{Butterfly sampling}

Butterflies were sampled with the utilisation of baited traps which were installed at both lower and upper levels. Traps were positioned at about $1.5 \mathrm{~m}$ above the ground for lower level, and $15-$ $22 \mathrm{~m}$ for the upper level. These cylindrical gauze-traps consisted of a cloth cylinder made of mosquito netting, were left open at the bottom to allow butterflies to enter (Haber, 2005). Baits were placed at the bottom of the trap to attract butterflies and consequently collected in the afternoon. Traps were set up by utilising the Single Rope technique, and thus the traps were suspended at the desired height. A total of five trees which were about $25 \mathrm{~m}$ apart were selected according to their height (15 to $22 \mathrm{~m}$ ), and two traps were installed individually, which gives a total of ten traps in. Physical environments for all trees were similar, and most of the trees selected were Sapotaceae.

Mashed, rotting bananas and pineapples were used as bait, and placed alternately between traps and individual trees (e.g. tree 1; ground - banana, canopy - pineapple, tree 2; ground - pineapple, canopy - banana). The odour of rotting fruits or any soft fruits were proven to be effective by previous studies (Beck \& Schulze, 2000; DeVries \& Walla, 2001; Dumbrell \& Hill, 2005; Fermon et al., 2000; Haber, 2005). Nymphalids are easily sampled in different spatial and temporal dimensions with the utilisation of baited traps (DeVries \& Walla, 2001). Bananas were mashed and kept in a container for about 48 hours prior to being used as bait (DeVries \&
Walla, 2001), while the pineapples were left rotting for about a week before placed in the traps.

Field sampling was conducted for 60 continuous days, from 26 July to 23 September 2007. On every sampling day, all traps were checked in the early afternoon (1400 hrs to 1500 hrs), and baits were replenished when necessary. Data such as collection date, number of individuals, weather condition and levels above the ground were also recorded.

\section{Identification and taxonomy}

Samples were identified by referring to Otsuka (1988) and the UNIMAS museum's voucher specimens. Data include number of individuals and list of species were recorded as well. All specimens were deposited at the UNIMAS Insect Reference Collections.

\section{Statistical Analyses}

Diversity indices which include Shannon index, Simpson and Margalef were used to measure the species diversity and diversity $t$-test was to compare the indices between strata. Comparisons of the number of individuals and species between two different levels (upper and lower levels) were tested with Mann-Whitney test, while for mean number of individuals and species were calculated with Mann-Whitney Rank Sum Test. For the correlation between nymphalids morphology (forewing length and body design index) and strata preference, analyses were carried out with Pearson Correlation test. Statistical analyses were performed with PAST version 1.96 (Hammer et al., 2001).

\section{Biometrical Measurement}

The observation of forewing size and body design of the nymphalids sampled was carried out in order to investigate the relationship between butterfly morphology and stratumspecific selection which may be influenced by predation and resource availability (Schulze et al., 2001). Forewing length (distance from wing base to apex), body length (distance from frons to tip of the abdomen) and also the maximum thorax width were measured with vernier caliper. Body length and thorax width were used to measure the body design index, which is the ratio of body length to thorax width. 
Slender built species were indicated with higher values, whereas the stouter ones with lower values (Schulze et al., 2001). Correlation between forewing length and body design index with the trap levels (ground or canopy) were tested with Pearson Correlation analysis, as conducted by Schulze et al. (2001).

\section{RESULTS}

\section{Overall Species Richness and Abundance along a Vertical Gradient}

A total of 104 individuals of fruit-feeding nymphalids representing 24 species from four subfamilies were sampled in this 60 days sampling period (Table 1). Comparisons between different trap heights in terms of species richness and abundance of fruit-feeding butterflies trapped along the vertical gradient (Figures 1 and 2) revealed that the ground level $(1 \mathrm{~m})$ sustained more species (Shannon-Weiner diversity indices: ground, $\mathrm{H}^{\prime}=1.17466$; canopy, $\left.\mathrm{H}^{\prime}=0.96077\right)$ and Zar $t$-test $(p<0.05)$. Raw summary data for the 60 days sampling period (26 July to 23 September 2007) resulted in a brief estimation of how the diversity and abundance of those fruit-feeding nymphalids varied within space and time.

Nymphalinae represents the most diverse subfamily at both levels, with nine $(42.86 \%)$ and five species $(45.45 \%)$ from the total species caught (24 species) at ground and canopy levels respectively. This subfamily also dominated both levels in terms of abundance, with ten individuals (55.56\%) at the canopy level; mostly Tanaecia munda. Correspondingly, 26 individuals (30.23\%) representing this subfamily were also sampled at the ground level, with strongest representatives of Lexias cyanipardus, Lexias pardalis and Tanaecia aruna (Table 1). However, statistically there was no significant difference of Nymphalinae between strata (Chisquare test; $p$-value $>0.05$ ).

Similar with Nymphalinae, Morphinae had the same proportion at the same level. Zeuxidia amethystus was recorded as the most abundant species for Morphinae (11 individuals).
Nevertheless, there was also no significant strata preference of the Morphinae (Chi-square test; $p$ value $>0.05)$. This result was also observed for Charaxinae (Chi-square test; $p$-value $>0.05$ ), which recorded the least individuals sampled in this study. Despite of the non-significant result for the three subfamilies, Satyrinae which recorded $22 \%$ from the total individuals sampled revealed a significant strata preference, which was the ground level (Chi-square test; $p$-value $<$ 0.05). Mycalesis anapita was the dominant species (11 individuals).

Thirteen species which represents $54.17 \%$ of the total species caught were found only at the ground level, $12.5 \%$ at the canopy level (three species), and $33.33 \%$ were sampled in both levels (eight species). The ground specialists are Prothoe franck (12 individuals), $M$. anapita (11 individuals) and Z. amethystus (11 individuals). Conversely, Euthalia merta, Elymnias nesaea, and Elymnias panthera were the only species which were unique to the canopy, represented by one individual, each.

On subfamily level, most of the fruit-feeding butterflies were represented at the ground level, and only subfamily Nymphalinae was recorded more than one average individual per day at the canopy level (Table 2 and 3). However, there was no significant difference in terms of species richness and abundance in all subfamilies, between these two strata.

\section{Vertical Stratification Patterns of Fruit- feeding Butterflies}

Overall total species richness and abundance data from both strata shows distinct distribution pattern of the nymphalids. This pattern reflected vertical distribution in species richness and abundance which decline with increasing heights (Figures 3 and 4). Significant difference in terms of number of nymphalids sampled was also revealed between strata (Mann-Whitney test, $p$-value $<0.05$ ). Similarly, the diversity at the ground level was significantly higher than at the canopy level (Diversity $t$-test, $p$-value < $0.05)$. 
Table 1. A taxonomic list of fruit-feeding butterfly species (Lepidoptera: Nymphalidae) and the number of individuals collected by using baited traps at two different heights above ground level, in a peat swamp forest, Kota Samarahan, Sarawak.

\begin{tabular}{|c|c|c|c|}
\hline \multicolumn{4}{|l|}{ Subfamily } \\
\hline Species & $\begin{array}{l}\text { Lower } \\
(0.5 \mathrm{~m})\end{array}$ & $\begin{array}{c}\text { Upper } \\
(15-22 \mathrm{~m})\end{array}$ & Total \\
\hline \multicolumn{4}{|l|}{ Satyrinae } \\
\hline \multicolumn{4}{|l|}{ Elymnias nesaea hypereides Fruhstorfer } \\
\hline 1902 & 0 & 1 & 1 \\
\hline Elymnias panthera labuana Staudinger 1889 & 0 & 2 & 2 \\
\hline Mycalesis amoena Druce 1873 & 1 & 0 & 1 \\
\hline Mycalesis anapita fucentia Fruhstorfer 1911 & 11 & 0 & 11 \\
\hline Mycalesis fusca adustata Fruhstorfer 1906 & 3 & 0 & 3 \\
\hline \multicolumn{4}{|l|}{ Mycalesis mineus macromalayana } \\
\hline Fruhstorfer 1911 & 1 & 0 & 1 \\
\hline Mycalesis patiana patiana Eliot 1969 & 4 & 0 & 4 \\
\hline
\end{tabular}

Morphinae

Amuthuxidia amythaon ottomana Butler

1869

Discophora necho cheops Felder 1867

Zeuxidia amethystus wallacei Felder 1867

Zeuxidia doubledayi horsfieldii Felder 1867

$\begin{array}{ccc}2 & 0 & 2 \\ 5 & 1 & 6 \\ 11 & 0 & 11 \\ 8 & 1 & 9\end{array}$

Nymphalinae

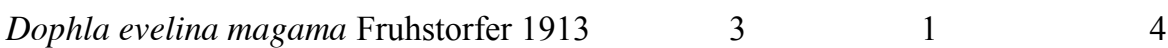

$\begin{array}{llll}\text { Euthalia iapis ambalika Moore 1858 } & 1 & 0 & 1\end{array}$

Euthalia merta apicalis Vollenhoeven $1862 \quad 0 \quad 11$

Euthalia monina bipunctata Vollenhoeven

1862

$1 \quad 2 \quad 3$

Lexias cyanipardus sandakana

Fruhstorfer1896

Lexias pardalis dirteana Corbet 1941

$5-0-5$

Rhinopalpa polynice helionice Fruhstorfer

1896

Tanaecia aruna aparasa Vollenhoeven 1862

Tanaecia clathrata coerulescens

Vollenhoeven 1862

Tanaecia munda munda Fruhstorfer 1899

$\begin{array}{lll}5 & 0 & 5\end{array}$

$\begin{array}{lll}1 & 0 & 1\end{array}$

$\begin{array}{lll}5 & 1 & 6\end{array}$

$\begin{array}{lll}1 & 0 & 1\end{array}$

$\begin{array}{lll}4 & 5 & 9\end{array}$

Charaxinae

Agatasa calydonia mahasthama Fruhstorfer

1913

Charaxes bernadus repititus Butler 1869

$\begin{array}{lll}1 & 1 & 2\end{array}$

$\begin{array}{lll}1 & 2 & 3\end{array}$

Prothoe franck borneensis Fruhstorfer $1913 \quad 12 \quad 0 \quad 12$

TOTAL (24 species)

$\begin{array}{lll}86 & 18 & 104\end{array}$ 


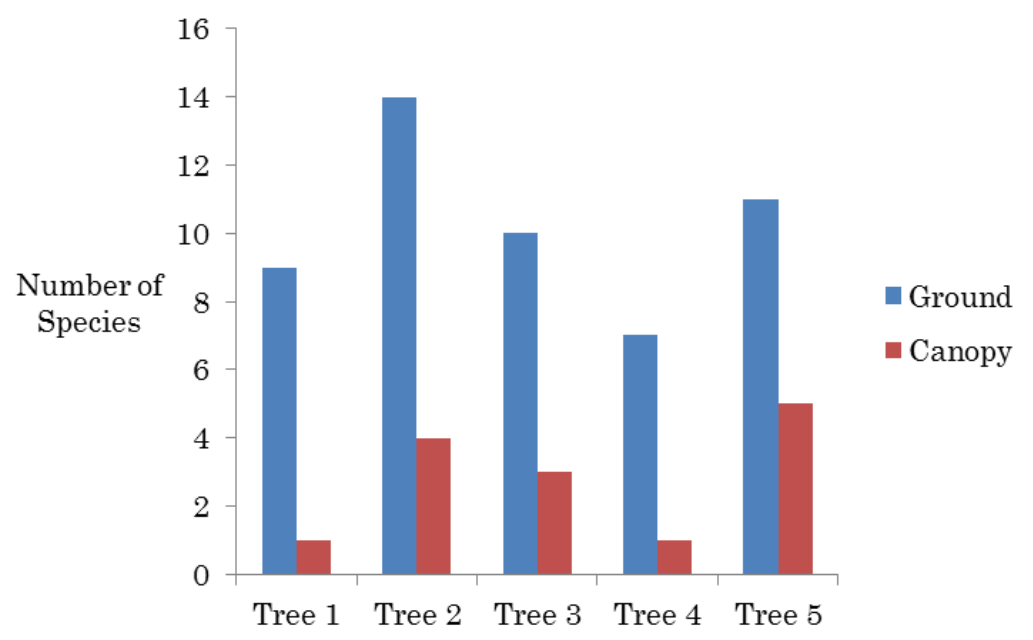

Figure 1. Number of species of fruit-feeding butterflies at the ground and canopy levels in a peat swamp forest, Kota Samarahan.

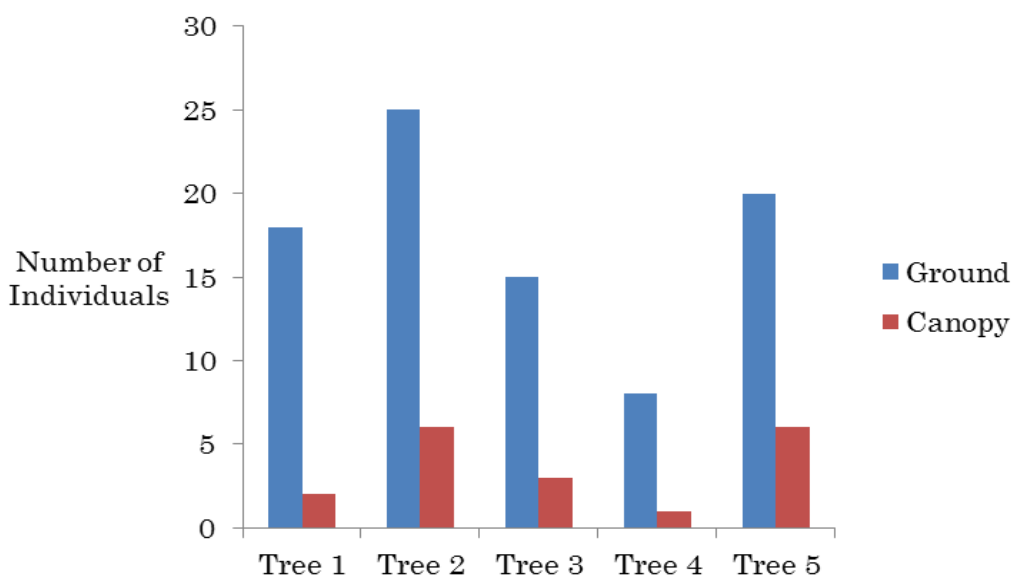

Figure 2. Number of individuals of fruit-feeding butterflies at the ground and canopy levels in a peat swamp forest, Kota Samarahan.

Table 2. Mean number of species of subfamilies Satyrinae, Morphinae, Nymphalinae and Charaxinae captured per day ( $\mathrm{n}=60$ for each stratum) at the ground and canopy levels.

\begin{tabular}{lcccc}
\hline \multirow{2}{*}{ Subfamilies } & \multicolumn{2}{c}{ Mean Species } & \multicolumn{2}{c}{ Mann-Whitney test } \\
\cline { 2 - 5 } & Ground level & Canopy level & \multicolumn{2}{c}{$p$-value } \\
\hline Satyrinae & 2 to 3 & 1 & ns & 0.1411 \\
Morphinae & 3 & 1 & ns & 0.1814 \\
Nymphalinae & 3 to 4 & 1 to 2 & ns & 0.0636 \\
Charaxinae & 1 to 2 & 1 & ns & 0.5050 \\
\hline
\end{tabular}


Table 3. Mean number of individuals of subfamilies Satyrinae, Morphinae, Nymphalinae and Charaxinae captured per day ( $\mathrm{n}=60$ for each stratum) at the ground and canopy levels.

\begin{tabular}{lcccc}
\hline \multirow{2}{*}{ Subfamilies } & \multicolumn{2}{c}{ Mean Individuals } & \multicolumn{2}{c}{ Mann-Whitney test } \\
\cline { 2 - 5 } & Ground level & Canopy level & ns & 0.0990 \\
\hline Satyrinae & 4 to 5 & 1 & ns & 0.0283 \\
Morphinae & 5 & 1 & ns & 0.0540 \\
Nymphalinae & 5 & 2 to 3 & ns & 0.6428 \\
Charaxinae & 2 to 3 & 1 & & \\
\hline
\end{tabular}

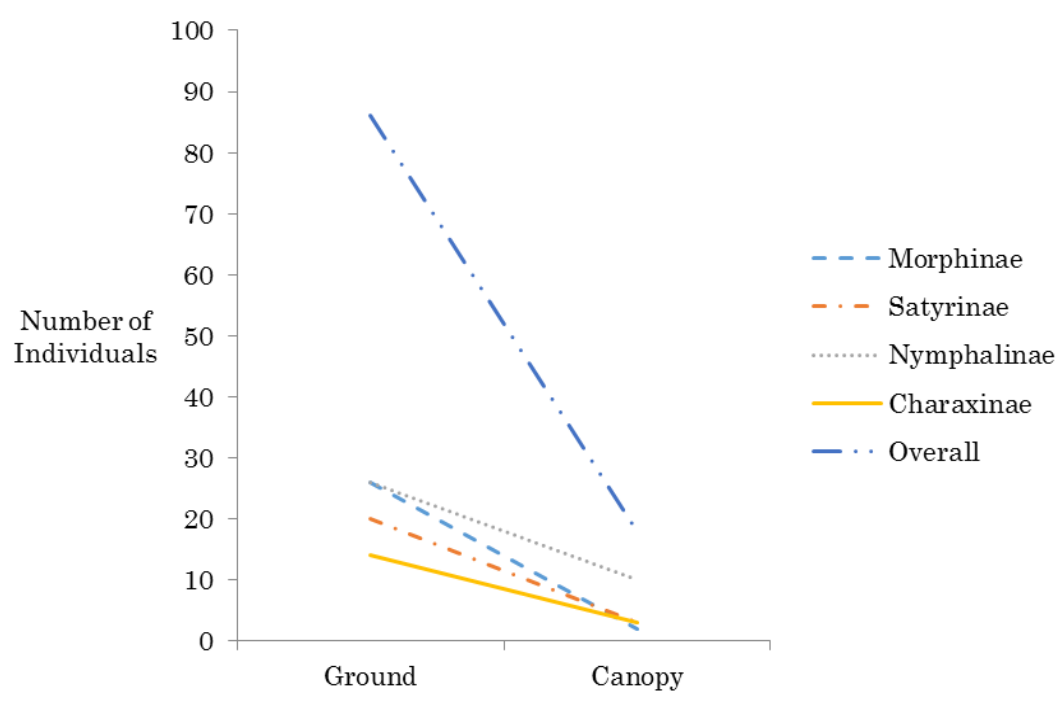

Figure 3. Decrease in abundance with increasing height patterns of Lepidoptera: Nymphalidae in a peat swamp forest, Kota Samarahan.

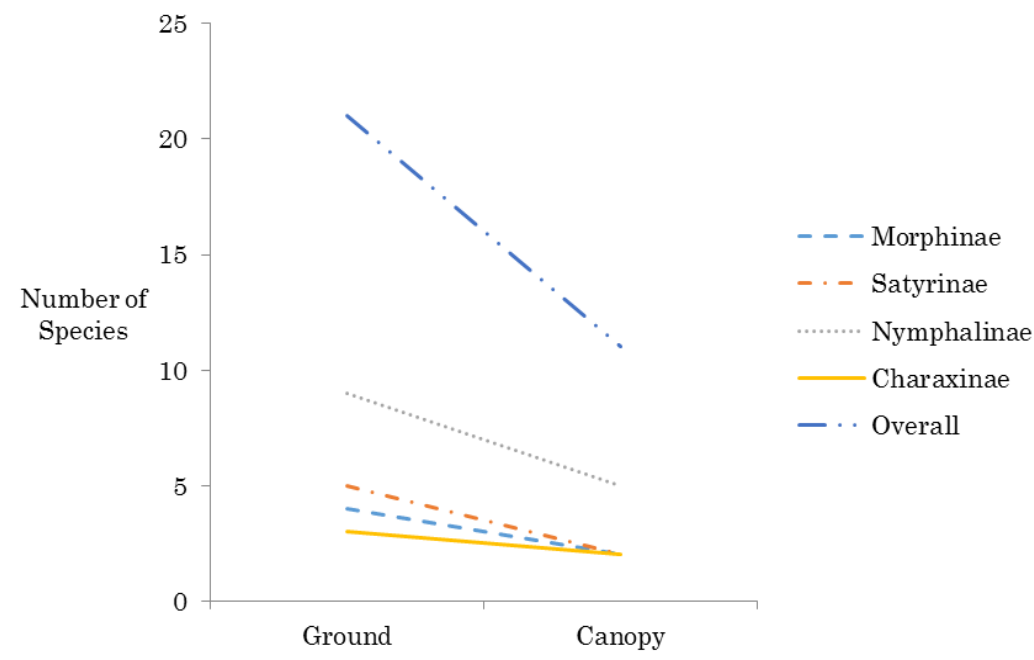

Figure 4. Decrease in species richness with increasing height patterns of Lepidoptera: Nymphalidae in a peat swamp forest, Kota Samarahan. 
Declining pattern of the species richness and abundance along the vertical gradient was observed in all subfamilies of the fruit-feeding butterflies, with the ground level sustaining higher diversity and abundance in all subfamilies (Figures 3 and 4). Accordingly, the average number of species and individuals captured for each subfamily also decreased with the increasing trap heights. However, statistically there was no significant difference of number of individuals and species between strata in all subfamilies (Table 2 and 3).

Forewing length of the fruit-feeding butterflies for both sexes was analysed for both ground and canopy levels. Overall, in the family level, there are no significant relationship between the trap heights and forewing length of the nymphalids, both for males (Pearson correlation: $\mathrm{r}=0.023, \mathrm{~N}=69, p=0.854)$ and females (Pearson correlation: $\mathrm{r}=-0.098, \mathrm{~N}=35$, $p=0.576$ ). Details on the forewing length for all species, including males and females are given in (Appendix 1). Most of the large (forewing lengths $\geq 45 \mathrm{~mm}$ ) Morphinae (Z. amethystus and Z. doubledayi), Nymphalinae (Dophla evelina and L. cyanipardus), and Charaxinae (Agatasa calydonia and $P$. franck), distinguished the nymphalids community at the ground level, and thus only a small proportion were sampled at the canopy (four individuals).

The relationship between trap height and forewing length may be biased, as most of the nymphalids sampled were restricted at the ground level. In order to minimize the taxonomic bias, separate analyses were done for the Satyrinae, Morphinae and Nymphalinae, yet no analysis for the female Charaxinae due to the small sample size. On subfamily level, a strong positive relationship between trap heights and forewing length of individuals for Satyrinae was revealed in females (Pearson correlation: $r=$ $0.958, \quad \mathrm{~N}=4, p<0.05$ ) and males (Pearson correlation: $\mathrm{r}=0.913, \mathrm{~N}=19, p<0.01)$. On the other hand, this relationship did not recur in Morphinae for both females (Pearson correlation: $\mathrm{r}=-0.247, \mathrm{~N}=16, \mathrm{p}=0.357)$ and males (Pearson correlation: $\mathrm{r}=-0.372, \mathrm{~N}=12, p$ $=0.234)$. No significant relationship was also found in Nymphalinae for females (Pearson correlation: $\mathrm{r}=-0.218, \mathrm{~N}=14, p=0.454)$ and males (Pearson correlation: $\mathrm{r}=0.068, \mathrm{~N}=22, p$ $=0.765)$ and also in male Charaxinae (Pearson correlation: $\mathrm{r}=0.157, \mathrm{~N}=16, p=0.562$ ).
The ratio of body length to maximum width of the thorax was used to quantify the body design. With this body design index, the slender ones were characterised by high ratios; meanwhile the stouter ones will be indicated by the lower values (Appendix 2). There is no significant relationship between mean ratios of body length to thorax width of the fruit-feeding nymphalids with the trap heights in both sexes (Pearson correlation for males: $\mathrm{r}=-0.158, \mathrm{~N}=69, p=$ 0.195 ; for females: $\mathrm{r}=0.157, \mathrm{~N}=35, p=0.367$ ).

To avoid any bias, analyses on the subfamily levels were also carried out, except for the female Charaxinae. No relationship recur in all analyses, except for the male Nymphalinae (Pearson correlation: $\mathrm{r}=-0.442, \mathrm{~N}=22, p=$ $0.04)$ which reveals a moderate negative relationship between those two parameters, and a strong positive correlation in the female Satyrinae (Pearson correlation: $\mathrm{r}=0.966, \mathrm{~N}=4$, $p<0.05$ ). The Satyrinae male (Pearson correlation: $\mathrm{r}=-0.053, \mathrm{~N}=19, p=0.828)$, Morphinae (Pearson correlation for males: $\mathrm{r}=$ $0.100, \mathrm{~N}=12, p=0.756$; for females: $\mathrm{r}=-0.271$, $\mathrm{N}=16, p=0.310$ ), female Nymphalinae (Pearson correlation: $\mathrm{r}=-0.231, \mathrm{~N}=14, p=$ 0.426), and male Charaxinae (Pearson correlation: $\mathrm{r}=0.115, \mathrm{~N}=16, p=0.671$ ) shows no significant relationship.

\section{DISCUSSION}

\section{Overall Species Richness and Abundance along a Vertical Gradient}

In this study, 86 individuals of fruit-feeding butterflies were sampled at the ground level, resulting to a significant difference in terms of the abundance between the two strata (MannWhitney test, $p<0.05$ ) (Table 1). This stratum also sustained higher species diversity (Shannon index $=1.17466$; Simpson's diversity index $=$ 0.9173; Margalef index $=4.490$ ), with 13 species unique to this level were recorded. This finding correlates well with DeVries and Walla (2001), which also found that the lower strata harbor higher species richness in their study at the Ecuadorian rainforest. Schulze et al. (2001) whom conducted a vertical study on the nymphalids in the Bornean tropical rainforest stated that the diversity of this guild of butterflies was higher at about $0-20 \mathrm{~m}$ above ground. 
However, Nymphalinae was the dominant subfamily sampled in both strata (Figure 3). According to DeVries and Walla (2001), Nymphalinae is a canopy flier, and rarely sampled in the lower strata if the canopy are distinctly high (Hamer et al., 2003). Nonetheless, due to the unique stratification of the peat swamp which was also a secondary forest (fragmentation resulted from former logging activities) the canopy is considered to range from $15-25 \mathrm{~m}$ high above the ground (Page et al., 1999). Furthermore, this subfamily attains diverse larval food plants, and thus more evenly distributed across strata (Schulze et al., 2001).

Morphinae shows high abundance and shared the same number of individuals with the Nymphalinae at the ground level, which makes them major specimens at this particular stratum (Figure 3). Characterised with broad wings, and slow-agile flight, these nymphalids are frequently sampled from the lower strata (Hamer et al., 2003; DeVries \& Walla, 2001). This was congruent with $Z$. amethystus which possess larger forewings than the other Morphinae butterflies. When constrained by food resource, the Morphinae shows strata preference as being a host specialist which prefers monocotyledonous food plants for the larva (Schulze et al., 2001). Apart from that, the adult butterflies also depend on rotting fruits which are usually found on the ground (Schulze \& Fiedler, 1998) as observed at the study site.

A low proportion of the Charaxinae species was recorded in this study, which only represent $12.5 \%$ of the total species caught throughout the sampling period (Table 1). Most of the Charaxinae trapped were restricted to the ground level, with only $17.6 \%$ of them sampled from the canopy. Nonetheless, the presence of fruits on the forest floor could have distracted the butterflies from the traps thus resulting to the less effectiveness of the traps, as it offers another alternative to the Charaxinae (Fermon et al., 2000). Furthermore, most of the Charaxes sp. will not fly during wet and overcast weather (Fermon et al., 2000), as almost $50 \%$ of the sampling period were rainy days. Regardless on the small representation of the Charaxinae, $P$. franck was sampled with the highest number of individuals in this study.
Most of the satyrine butterflies were encountered at the lower strata, which correlates well with studies done by DeVries and Walla (2001) in the Ecuadorian rainforest and Schulze et al. (2001) in the Bornean tropical rainforest. Among those species listed, two of them are only sampled at the canopy, namely $E$. nesaea and E. panthera. The rest of the samples were represented by the genus Mycalesis, which comprised of mostly lowflying butterflies that prefer shaded area of the forest undergrowth (Corbet \& Pendlebury, 1992; Hamer et al., 2003). Closely related with the Morphinae, this subfamily shares the same traits, which are slow-agile fliers and encountered most in the lower level (Hamer et al., 2003).

Overall result of this study shows that the butterfly species in the peat swamp forest exhibit different strata preference, with some of them observed to be confined only to certain strata while some were sampled in both strata. Various factors could have contributed to this preference, which include the morphological characteristics of the fruit-feeding butterflies (broad wings for satyrine butterflies), the availability of food resources as well as larval food plants at certain strata, and the variation of microclimatic conditions.

Nevertheless, the occurrence of some of the fruit-feeding butterflies in both strata (Discophora necho, Z. doubledayi, D. evelina, E. monina, T. aruna, T. munda, A. calydonia, and $C$. bernadus) may probably resulted from the presence of predators such as insectivorous birds, as suggested by Schulze et al. (2001). Even though there was no proper study on the presence of predators in this study, A. calydonia which was sampled at both levels (one individual respectively) did exhibit broken hind wings with a clear beak-mark at the dorsum part (both specimens), that proved the occurrence of insectivorous birds in this forest. According to Fermon et al. (2000), in relation to humidity, temperature and light, some of the butterflies experienced heliophobia which occur due to the lower relative humidity and higher temperature. This caused the particular butterfly to return to the shade after a few minutes, due to the weather. This probably explained the presence of the same species in both strata, apart from the lower canopy which 
characterized the peat swamp forest (Page et $a l ., 1999)$. Nonetheless, this can only be true in the more open areas, such as forest gaps, and during sunny days.

\section{Vertical Stratification Patterns of Fruit- feeding Butterflies}

Generally, the fruit-feeding nymphalids show a declining pattern in diversity and abundance with increasing height (Figure 3 and 4). This pattern was similarly observed in Poring hill dipterocarp forest, Sabah, except for the Nymphalinae (Schulze et al., 2001). Significantly higher number of fruit-feeding butterfly at the ground level could be attributed to the rich plant diversity which provide larval resources (for certain species) as most of the butterflies are host-plant specific (Schulze et al., 2001). The presence of rotting fruits on or near the ground also prominently restricts the occurrence of most of the fruit-feeding butterflies, especially Morphinae (Abang \& Karim, 2005). These explain the declining pattern from the ground to the canopy level in the present study. Other factors could be the presence of predators such as insectivorous birds and the variation of microclimatic conditions which may also contribute to the differentiation of the nymphalids across the vertical gradient (Schulze et al., 2001).

In the present study, few species were spotted to be confined to the ground level, and appeared to be the most sampled. All twelve individuals of $P$. franck were recorded which comprised of males. This finding correlates well with Schulze sampled most of this species between $0 \mathrm{~m}$ to $20 \mathrm{~m}$ above ground level. Additionally, most of the tropical butterfly species especially male Charaxinae were seen to take up water and nutrients from the ground, especially at moist sites (Schulze et al., 2001) which explain the presence of $P$. franck at the ground instead of at the canopy in this study.

$M$. anapita and Z. amethystus were also listed only at the ground level with 11 individuals recorded, respectively. The satyrine butterfly from the genus Mycalesis is known to be a local forest dweller, and thus commonly encountered especially in the lower level (Corbet \& Pendlebury, 1992). On the other hand, Z. amethystus of subfamily Morphinae is known to be common in the dense forest, and the females are rarely to be sampled (Corbet \& Pendlebury, 1992). Nevertheless, females were recorded to be more abundant than the males in this study; probably due to the presence of Palmae sp. in this forest which are known to be their host plant (Corbet \& Pendlebury, 1992).

Small windows of sunshine between the tree canopies may have been sufficient enough to trigger butterfly activity in the canopy (DeVries \& Walla, 2001). This is observed for the Nymphalinae, which are known to be 'sunlovers' and strong fliers, a full package to be canopy fliers (Corbet \& Pendlebury, 1992). Accordingly, this subfamily appears to be the most diverse in the canopy, as well as comprising about half of the total specimens in this particular stratum.

On the other hand, presence of epiphytes which occupied the upper stratum and act as 'traps' could retain rotting fruits, and thus produced a biased result (Schulze et al., 2001). This explained the presence of the satyrine butterflies which were sampled in the canopy, $E$. nesaea and E. panthera, which are actually known to be forest dwellers that prefer shady area (Corbet \& Pendlebury, 1992). Apart from that, an attribute of both species is their wide forewing compared to other satyrines, also allows them to maneuver at the upper level.

Morphological trends in terms of body shapes and forewing length of the fruit-feeding butterflies were also analysed in this study. According to Schulze et al. (2001), in the ecological studies of arthropods, sizes are often analysed in order to characterize and compare between communities, as well as an indicator to study the influence of certain abiotic and biotic factors on the ecology of insects. In this study, the morphology of the fruit-feeding butterflies was analysed in order to give a vivid picture of the correlations of the trap heights with their physical characteristics.

Even though there was no significant relationship between the forewing length and the trap heights for the overall nymphalids, analyses for each subfamily revealed that the forewing of the satyrine butterflies were larger with increased trap heights. Conversely, similar analyses done by Schulze et al. (2001) found that no significant relationship is observed for 
the satyrine butterflies, yet negative relationship occurs in the Nymphalinae. This indicates that the large forewing (compared with at the lower level) of the satyrine butterflies in the canopy characterized the nymphalids in the peat swamp forest, compared with those in the tropical rain forest.

Body index of the fruit-feeding butterflies is used as indicator for the flight characteristics (Schulze et al., 2001). For this analyses, significant relationship was also absent for overall nymphalids, yet it was revealed only in the male Nymphalinae and female Satyrinae. The significant relationship indicates that the canopy layer sustained stouter bodied male Nymphalinae (E. merta, E. monina, T. munda, $T$. aruna), and slender-built female Satyrinae (E.nesaea).

According to Schulze et al. (2001), Bornean fruit-feeding butterflies of the canopy layers are predicted to be more persistent fliers than their counterparts in the ground level. Apart from that, stouter-bodied nymphalids are better in escaping attacks from insectivorous birds, which explained this morphological trend in the canopy (Schulze et al., 2001). This body design also paired with strong wings, which will acquire high flight speeds, as well as to bear the high wind speed in the canopy (Schulze et al., 2001). On the other hand, the slender-bodied butterflies have an excellent maneuverability, to adapt with the dense vegetation in the lower strata (Schulze et al., 2001). The occurrence of the slender bodied E. nesaea in the canopy is due to the presence of epiphytes such as $A$. nidus, which has been explained, as well as their wide forewing which gives them extra credits to adapt to the upper levels.

\section{CONCLUSION}

Overall, vertical distribution of the fruit-feeding butterflies was observed in both diversity as well abundance in this study. There was a significant difference between strata and revealed higher diversity as well as abundance at the ground level. Possible factors which contribute to this include food resource availability and predators. The unique forest stratification of the peat swamp forest in compared with other forest types may also determine the species occurrence of the nymphalids.
In terms of strata preference, relationship with morphological characteristics of the fruitfeeding butterflies was also analysed. Stouterbodied of male Nymphalinae and slender-built body of female Satyrinae were sampled more at the canopy level. These physical attributes help these nymphalids to have better flight activity. On the other hand, both satyrine sexes which were sampled at this stratum were found to have larger forewing, which helps them to maneuver better.

Although the data shows the stratification of the fruit-feeding butterflies, this result may not apply to the vertical distribution of other behavioural context, such as courtship and resting behaviour, as this study had only manipulated the feeding activity of this guild (Schulze et al., 2001). However, the study of this guild of butterflies has proven to be a descriptive assessment method especially being an indicator of the habitat status (Fermon et al., 2000). Studies that emphasized on the ecological aspect of this biological indicator have been more utilised and conducted extensively. Especially for future reference, apart from contributing in scientific documentation, such studies bring more knowledge to the forest management.

\section{REFERENCES}

Abang, F. \& Hill, D.S. (2006). The Invertebrate Fauna. In Abang, F. and Das, I. (Eds.), The Biodiversity of a Peat Swamp Forest in Sarawak. Kota Samarahan, Universiti Malaysia Sarawak. Pp 87-98.

Abang, F. \& Karim, C. (2005). Diversity of Macromoths (Lepidoptera: Heterocera) in the Poring Hill Dipterocarp Forest, Sabah, Borneo. Journal Asia-Pasific Entomology, 8(1): $69-79$.

Beck, J. \& Schulze, C.H. (2000). Diversity of Fruit-feeding Butterflies (Nymphalidae) Along a Gradient of Tropical Rainforest Succesion in Borneo with Some Remarks on the Problem of "Pseudoreplicates". Transactions of the Lepidopterological Society of Japan, 51(2): 89 - 98. 
Butler, T. (2005). Studying the Rainforest Canopy, Learning About the Richest Region of the Forests. Crane's Eye View.http://news.mongabay.com/2005/033 1-tina but ler.html. Downloaded on 11.07.2007.

Corbet, S. \& Pendlebury, H.M. (1992). The Butterflies of the Malay Peninsula. Kuala Lumpur. Malayan Nature Society. Pp 595.

DeVries, P.J. \& Walla, T.R. (2001). Species Diversity and Community Structure in Neotropical Fruit-feeding Butterflies. Biological Journal of the Linnean Society, 74:1-15.

Dumbrell, A.J. \& Hill, J.K. (2005). Impacts of Selective Logging on Canopy and Ground Assemblages of Tropical Forest Butterflies: Implications for Sampling. Biological Conservation, 125(1): 123-131.

Fermon, H., Waltert, M., Larsen, T.B., Dall'Asta, U., \& Muhlenberg, M. (2000). Effects of Forest Management on Diversity and Abundance of Fruit-feeding Nymphalid Butterflies in South-eastern Cote d'Ivoire. Journal of Insect Conservation, 4:173- 189.

Haber, E. (2005). Baseline Assessment of Butterfly Biodiversity and Community Composition at the Firestone Center for Restoration Ecology, Costa Rica. Research Reports of the Firestone Center for Restoration Ecology. Pp 21.

Hamer, K.C., Hills, J.K., Benedick, S., Mustaffa, N., Sherratt, T.N., Maryati, M., \& Chey, V.K. (2003). Ecology of Butterflies in Natural and Selectively Logged Forests of Northern Borneo: The Importance of Habitat Heterogeneity. Journal of Applied Ecology, 40: 150-162.
Hammer, Ø., Harper, D. A. T., \& Ryan, P. D. (2001). PAST: Paleontological Statistics software package for education and data analysis (Version 1.96) [Computer software]. Palaentologia Electronica, 4(1): 9.

Otsuka, K. (1988). Butterflies of Borneo. Japan: Tobishima Corporation.

Page, S.E., Rieley, J.O., Shotyk, O.W. \& Weiss, D. (1999). Interdependence of Peat and Vegetation in a Tropical Peat Swamp Forest. Philosophical Transactions: Biological Sciences, 354 (1391):18851897.

Schulze, C.H., Linsenmair, K.E. \& Fiedler, K. (2001). Understorey versus CanopyPatterns of Vertical Stratification and Diversity among Lepidoptera in a Bornean Rainforest. Plant Ecology, 153:133-152.

Schulze, C.H. \& Fiedler, K. (1998). Habitat Preference and Flight Activity of Morphinae butterflies in a Bornean rainforest, with a Note on Sound Production by Adult Zeuxidia (Lepidoptera: Nymphalidae). Malayan Nature Journal, 52: 163-176.

Zainudin, R. (2006). The Amphibian Fauna. In Abang, F. and Das, I. (Eds.), The Biodiversity of a Peat Swamp Forest in Sarawak,. Kota Samarahan: Universiti Malaysia Sarawak. Pp $107-114$. 


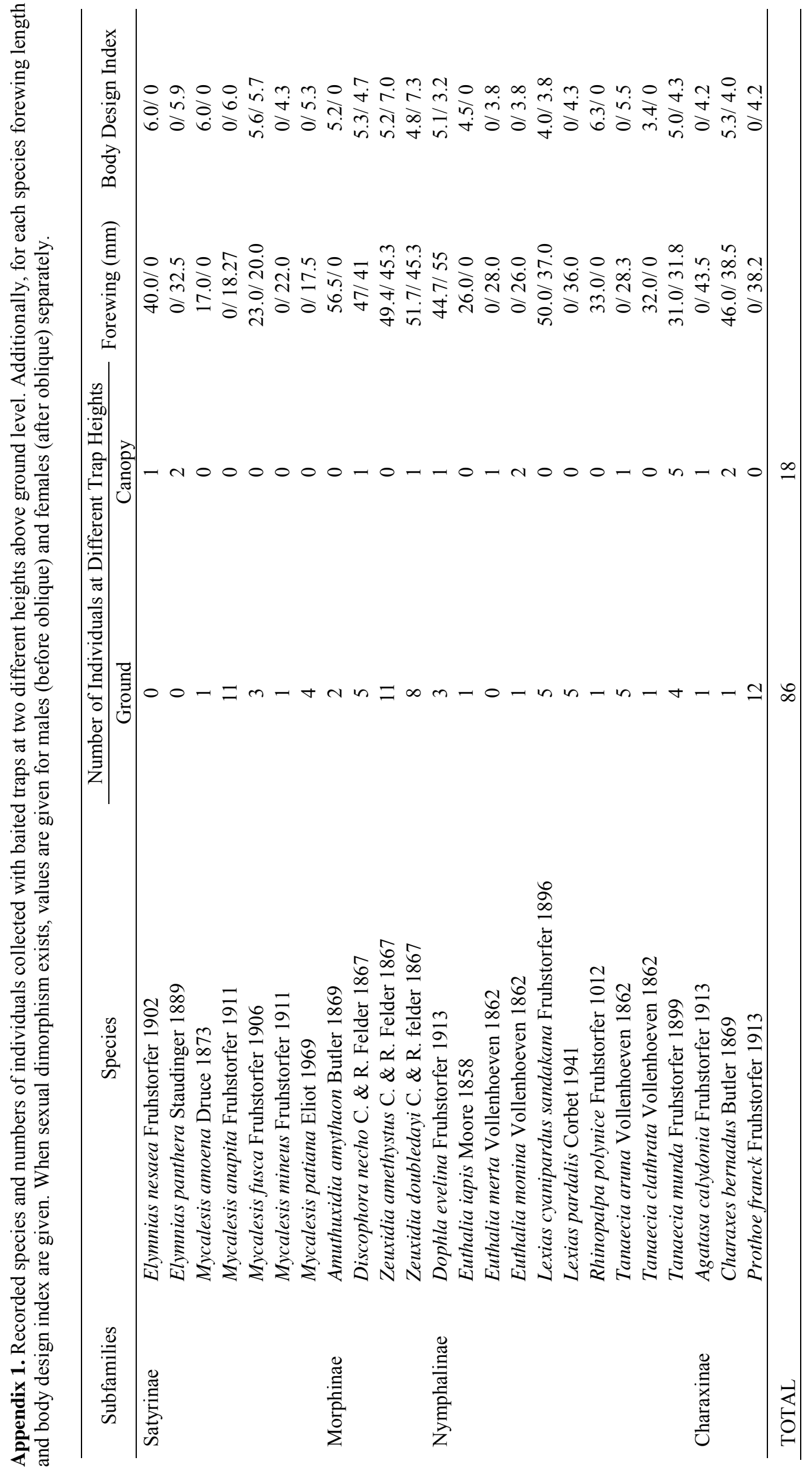

